\title{
THE DEVELOPMENT OF A DIAGNOSTIC 'PROJECT MANAGEMENT CULTURE’ ASSESSMENT TOOL (PART 2)
}

\author{
YVONNE DU PLESSIS \\ CRYSTAL HOOLE \\ yvonne.duplessis@up.ac.za \\ Department of Human Resources Management \\ University of Pretoria
}

\begin{abstract}
The growing interest in project management as a management approach requires organisations to adopt an operational culture that supports project management principles and practices. The availability of an empirically developed assessment tool would enable organisations to assess their present organisational culture's readiness for project work. The aim of this study is to develop a diagnostic instrument that can measure the operational 'project management culture' in organisations. The final tool (PMCAT) comprises of a five-factor scale. The overall reliability of the items in this scale was highly acceptable with a Cronbach alpha above 0,70 . The tool has a high validity with a inter- item correlation above 0,32 .
\end{abstract}

Key words

Project management culture, diagnostic assessment tool

The purpose of this study is to develop a holistic diagnostic tool to measure the operational project management culture in organisations. In order to develop a diagnostic measurement tool, the literature on scale development had to be explored and thoroughly understood. The literature study reveals a variety of often conflicting theoretical positions and a lack of empirical support for many of the measures of organisational culture. The development of a project management culture assessment tool should therefore reflect the emerging research perspectives on organisational culture, project management culture and scale development.

The literature was surveyed from a multi-disciplinary point of view to ensure a thorough theoretical foundation. This is especially necessary to overcome negative critiques on the development of organisational culture tools and in this instance the project management culture assessment tool and the dimensions included in the instrument. The model or theoretical framework on which this assessment tool was developed is based on intensive previous research by Du Plessis (2001, 2003)

One of the main problems related to research in this field is that project management culture has not been clearly defined. Research conducted in the field of project management culture is limited and focuses mainly on sub-sections of project management culture such as project management profession culture (Wang, 2001), project team culture (Gray \& Larson, 2003) a supportive project environment (Graham \& Englund, 1997), or the role that the project manager, project team, systems and process play on project success (Kendra \& Taplin, 2004).

Many authors in Project Management use the terms 'project culture', 'project management culture' and 'organisational culture' interchangeable. These terms are related, because it refers to culture, but do not have the same meaning as it is conducted within a different context. In essence, 'organisational culture' refers to a system of shared norms, beliefs, values and assumptions that bind people together within the organisation (Ball \& Asbury, 1989; Schein, 1984). The organisational culture directs the behaviour of its members and is thus manifested in the verbal and non-verbal behaviour of its members. The literature states that organisational culture does contribute towards business success (Ashkanasy, Wilderom \& Peterson, 2000; Furnham \& Gunter, 1993; Kotter \& Heskett, 1992).

'Project culture' refers to the culture within a project, thus the behaviour of the project team members, and contributes towards project success (Cleland, 1994; Turner \& Simister, 2000). 'Project management culture' is viewed as the broader construct of behaviour of all stakeholders within an organisational setting where project work has to be delivered (Du Plessis, 2001) and is by nature systemic and consists of interdependent parts (Kerzner, 1997).

In order to address the fragmented nature of previous research on project management culture, an operational project management culture framework was developed by Du Plessis (2001; 2003). The term 'project management culture' in organisations should be viewed as a holistic phenomenon, inclusive of strategies, structures, systems, processes, people's behaviour and the environment in which the project has to be delivered (Du Plessis, 2003).

The operational organisational culture definition by Deal and Kennedy (1982), "the way we do things around here" was used as base to construct an operational project management culture definition and framework. This project management culture framework, as reflected in Figure 1, consists out of four main dimensions: project processes (the way), people in projects (we), systems and structures used in project management (do things) and the project environment (around here).

The project process dimension included descriptive elements such as project life-cycle phases; results and speed of delivery; controlled/disciplined procedures; learning and continuous improvement and customer orientation and systems thinking. The people dimension referred to aspects such as people's behaviour in projects, socio-cultural aspects such as interpersonal relationships, stakeholder commitment, affinity for conflict, learning orientation, results orientation, open-systems thinking, team orientation and interdependence. The systems and structure dimension referred to 
aspects such as project methodology, tools and techniques used in project management. The environment dimension related to internal and external aspects influencing the way in which the project is being managed: such as strategic emphasis, upper management support; project planning support; customer/end-user support; project execution support; communication and information flow across boundaries and general organisational support with project execution.

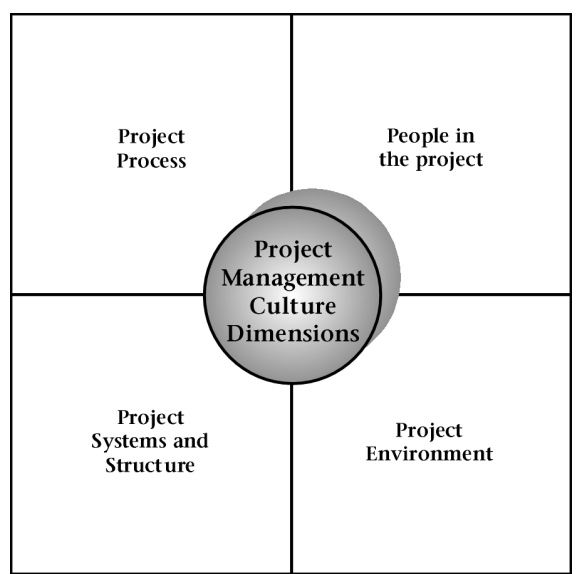

Figure 1: Project Management Culture dimensions

\section{RESEARCH DESIGN}

Research approach

This study is methodological, and can be classified as an exploratory and descriptive study, as it aims to develop and validate a new instrument. Both inductive and deductive modes of reasoning are used (Mouton, 2005).

Hofstede and Neuijen (1990) suggest that in measuring organisational culture it is advisable to start "with a qualitative orientation and then followed up with a quantitative verification. Determine which operationable and independent dimensions can be used to measure them, and how do these dimensions relate to what is known about organisations from existing theory and research". In measuring project management culture, a similar approach should be adopted. The research methodology used in developing a scale instrument is therefore inclusive of qualitative and quantitative methods. The process of scale development, as described by De Vellis (1991) and supported by Clark and Watson (1995), was used as theoretical base for developing the project management culture assessment tool in this study.

De Vellis (1991) states that in the 'quantification of a particular phenomenon in research where there are either inappropriate or unavailable measurement tools, the development of a measurement instrument seems to be the only option'. The social sciences often measure elusive, intangible phenomena derived from multiple, evolving theories and thus pose a clear challenge to research (De Vellis, 1991). Therefore knowledge about the specific phenomenon or construct being studied is probably the most important consideration in developing a measurement scale.

\section{Research methodology}

Participants

Two different sampling groups were used, one group for the verification part of the theoretical construct and another for the development of the assessment tool. The biographical information of the sample groups can be seen in Table 1 and 2.
The sample group for the verification part of the study comprised of seventy (70) project management experts who were practicing project managers and academics in project management from various South African industries and academic institutions. These individuals are viewed as experts who practice project management in the broader project management field, from a technical, process and research point of view. Participants were chosen non-randomly. A criterion in the participant selection was that all the participants had to be experienced in project management, either as project manager or as project team member for at least five years and have a project management qualification. Of the 70 questionnaires sent out, 52 were returned unspoiled. The number of responses $(n=52)$, represents a $74 \%$ response rate.

TABLE 1

BIOGRAPHIC INFORMATION ON THE PROJECT MANAGEMENT EXPERT SAMPLE $(\mathbf{N}=\mathbf{5 2})$

\begin{tabular}{|c|c|c|c|c|c|}
\hline $\begin{array}{l}\text { Type of } \\
\text { industry }\end{array}$ & \multicolumn{4}{|c|}{$\begin{array}{l}\text { 1. Service (e.g. Banking, Education, Government) } \\
\text { 2. Technical (e.g) Engineering/Manufacturing) }\end{array}$} & $\begin{array}{l}24 \\
28\end{array}$ \\
\hline $\begin{array}{l}\text { Type of } \\
\text { projects }\end{array}$ & \multicolumn{4}{|c|}{$\begin{array}{l}\text { a. Technical ('hard-side' e.g. production, } \\
\text { manufacturing) } \\
\text { b. Non-technical ('soft-side' e.g. processes, } \\
\text { service delivery) }\end{array}$} & $\begin{array}{l}22 \\
30\end{array}$ \\
\hline \multicolumn{2}{|c|}{$\begin{array}{l}\text { Years of projects } \\
\text { work experience }\end{array}$} & $\begin{array}{l}5-10 \text { yrs } \\
6\end{array}$ & $\begin{array}{l}11-15 \text { yrs } \\
17\end{array}$ & $\begin{array}{c}16-20 \text { yrs } \\
19\end{array}$ & $\begin{array}{c}21+y r s \\
10\end{array}$ \\
\hline \multirow{2}{*}{\multicolumn{2}{|c|}{ Qualification }} & $\begin{array}{l}\text { Bachelor's } \\
\text { degree }\end{array}$ & $\begin{array}{c}\text { Honour's } \\
\text { degree }\end{array}$ & $\begin{array}{c}\text { Master's } \\
\text { degree }\end{array}$ & $\begin{array}{c}\text { Doctoral } \\
\text { degree }\end{array}$ \\
\hline & & 4 & 18 & 24 & 6 \\
\hline
\end{tabular}

The respondents represented both the technical ('hard side') and non-technical ('soft side') of projects. It is clear from the biographical information in table 1 that the sample group is well educated and experienced in the field of project management across a broad spectrum of industrial sectors. The respondents are all well-qualified: more than $50 \%$ have master's or doctoral degrees and more than $80 \%$ have in excess of ten years of project experience. A valid assumption can be made about their expertise and balanced representation of technical (54\%) and non-technical (46\%) industries regarding their viewpoints on the validity of the theoretical construct.

The sample group for the development of the assessment tool made use of 494 practicing project managers and experienced project team members. They were non-randomly chosen from a database of students who had successfully completed project management training, during 1999-2001 at the University of Pretoria, and who were working in project environments. The rule of thumb in scale development is that approximately 300 responses are necessary to successfully factorise items (De Vellis, 1991). However, since the items in the questionnaire were divided into sub-scales on the basis of the theoretical model of Du Plessis (2003), the number of responses could be less than 300 (the "rule of thumb" often used is five responses per item) (Gorsuch, 1997). The maximum number of items per sub-scale was 48 ; therefore the minimum number of responses needed was $240(5 \times 48)$. Of the 494 questionnaires sent out, 236 were returned unspoiled. The number of unspoiled responses $(n=236)$ represents a response rate of $48 \%$. This number of responses was adequate to continue with scale development.

The biographical information in table 2 indicates that the sample group is experienced in project management. It also shows that the sample group represented a total industry perspective across various cultural groupings (especially relevant in the South African context) 
TABLE 2

BOIGRAPHICAL INFORMATION ON THE SCALE DEVELOPMENT SAMPLE GROUP OF PROJECT MANAGERS AND PROJECT TEAM MEMBERS (N = 236)



\section{Measuring instrument}

\section{Scale development}

Step 1: Determine the purpose of what is to be measured

A thorough theoretical base must be developed as an aid to clarity, therefore the theoretical framework must be clear and the boundaries of the phenomenon to be tested must be identified. If there is no theory available to guide the research, a conceptual framework must be developed before developing the scale instrument. A tentative theoretical model, based on a thorough literature review, must be specified to serve as a guide to scale development. Thinking through and not just about the theoretical issues and understanding the underlying constructs prior to entering into the process of scale construction increases the likelihood that the resulting scale will contribute to theory.

A general definition (broader description) or a specific (narrow) set of measurement must be done. An active decision should be taken about the specific purpose of the instrument. It is not enough to generate a set of items and then see whether they fit the purpose. Scale specificity can vary along a number of dimensions, including content domains, setting (specific environment) or population.

Be clear about what to include in a measure, as well as what to exclude. Thus make sure the underlying construct is well defined and is focused on the main purpose.

Step 2: Generate an item pool

The goal is to arrive at a set of items, some of which indicate a high level of latent variable when endorsed and others with a high level of latent variable when not endorsed. Choose items that reflect the scale's purpose. DeVellis, (1991) mentioned the rule: 'Start with 40 items and end with 10 items'. However, in the elimination process ensure that the theoretical construct is not lost because of removing items unnecessarily (Hofstede \& Neuijen, 1990). Each content area must be well represented in the initial item pool. This process is referred to as the 'theoretical-rationale or deductive method' of scale development (Clark \& Watson, 1995). An ideal to strive for is that every item should be accounted for based on the theoretical construct to ensure content validity. Good scale construction is an evolving and iterative process. Items should also be written well, ensuring that the items are easy to read and to comprehend.
Step 3: Determine the format for measurement

Usually two dominant response formats are used in assessments, dichotomous 'true-false or yes-no' scales and the Likert-type rating scales. The Likert-type scale is viewed as a more acceptable and appropriate measurement scale, because it provides a wider choice of options and is thus more reliable and stable. A desirable quality of a measurement scale is variability. The number of response options included in the Likert-type scale also needs careful consideration to fit the research. Equal number options can result in respondents' falling on one side, whereas midrange options can result in respondents' choosing the middle option.

Step 4: Have initial item pool reviewed by a pool of experts

It is advisable to have the initial item pool validated by a pool of experts who can add value by:

- confirming or invalidating the inclusion of an item;

- evaluating the items' clarity and conciseness; and/or

- pointing out ways to expand items.

Lawshe's (1975) quantitative approach to the content validity of items was applied in this study. The judgment of subject matter experts in the field, are regarded as the highest authority to challenge the 'purported content validity of the test'. The formula for content validity is expressed as a ratio, the 'content validity ratio- CVR'.

CVR $=\frac{\text { ne-N/2 }}{\mathrm{N} / 2}$

Where;

ne $=$ number of respondents who indicate the item as essential

$\mathrm{N}=$ the total number of respondents

The CVR is negative if fewer than half say an item is 'essential', and positive when more than half say it is 'essential'. Thus, the more respondents over $50 \%$, perceive the item as 'essential', the greater the extent or degree of its content validity.

Therefore the content validity ratio (CVR) is an item statistic that is useful in the rejection of specific items from the initial item pool and the computation of the content validity index (CVI - the mean of the CVR values retained in the test) for the whole item pool. 
Step 5: Consider the inclusion of validated items

Ensure that the items are valid by conducting applicable validity tests to check:

- content validity (representative sample of items);

- criterion validity (predictive validity, which is more a practical than scientific validity); and

- construct validity (theoretical relationship of a variable to other variables).

Step 6: Administer the items to a development sample

Include the validated items in the questionnaire, together with new items (if applicable) and expose it to a sample of subject experts. The sample size recommended by De Vellis (1991) as well as Clark and Watson (1995) are around 300 respondents.

Step 7: Evaluate the items

Evaluate the items to determine which ones to include or retain from the item pool. Clark and Watson (1995) recommended an inter-item correlation of 0,15 to 0,5 . The ultimate goal of scale development according to Clark and Watson (1995) is to maximize validity rather than reliability. Internal consistency reliability is concerned with the homogeneity of the items comprising a scale and is typically equated with the Cronbach's coefficient alpha. Item-scale correlation indicates to what degree items inter-correlate with each other. The items with an alpha correlation of 0.70 and higher are viewed as acceptable (Cortina, 1993).

Step 8: Optimise scale length using factor analysis

At this stage the pool of items should demonstrate acceptable reliability. Factor analysis should now be used to optimise the scale length. Hair, Anderson, Tatham and Black (1998) describe factor analysis, as 'a generic name given to a class of multivariate statistical methods whose primary purpose is to define the underlying structure in a data matrix'. Thus its purpose is to construct common underlying dimensions in which the individual items can be grouped. Factor analysis could have an exploratory or confirmatory perspective. Exploratory Factor Analysis (EFA) is useful in searching for structure among a set of variables. Confirmatory Factor Analysis (CFA) assesses the degree to which the data fits the expected structure, as supported by literature or prior research. Factor analysis generally requires the number of cases to be much larger than the number of variables, although various authors remain vague on the allowable limit: 'Unfortunately, nobody has yet worked out what a safe ratio of the number of subjects to variables is' (Gorsuch, 1983). A ratio of five to ten subjects per item is advised by De Vellis (1991). A general conclusion stated in Gorsuch (1997) is that the "sample size needed is a function of the stability of a correlation coefficient without any correction needed for the number of variables". Kaiser's eigenvalue rule is used to extract the factors that explain more variance (Kaiser, 1970). Eigenvalues higher than 1.0 can be considered for inclusion as a factor.

The reason for wanting a large number of subjects is that factors can become unstable and unduly dependent on the interpretation of individual respondents. To avoid such pitfalls it is therefore wise to keep the number of factors small, - much smaller than the number of cases and smaller than what is technically possible based on 'eigenvalues' larger than 1,0. Also, one should only consider variables with loadings higher than 0,50 on a factor. However one should keep the underlying theoretical construct in mind (Hofstede \& Neuijen, 1990).

The complexity of the construct and research questions in this study necessitated the use of a triangulation approach (multiple methods), as expressed in the literature review.

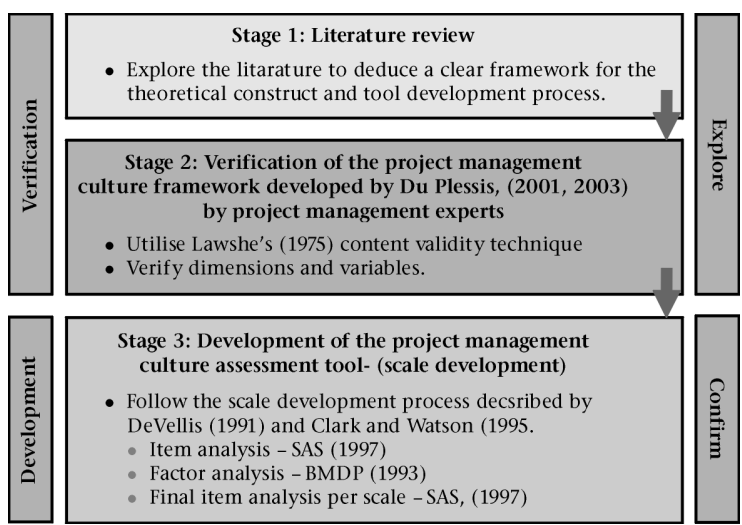

Figure 2: Research Design and Process

This research process was therefore divided into three stages as illustrated in Figure 2, being:

- A literature study that was done to comprehend the context of the multidisciplinary fields involved and to provide a clear theoretical framework as the basis on which the desired project management culture assessment tool could be developed.

- Verification of the project management culture framework and elements developed by Du Plessis (2003). This verification was done by project management experts. This stage involved the use of a qualitative perception questionnaire and some means of quantification utilising Lawshe's (1975) quantitative approach to content validity.

- Project management culture assessment tool development by utilising research inputs from previous researchers as mentioned in the literature.

\section{Methods of data gathering and analysis of data}

The method of data gathering in the verification part of the theoretical construct was done by distributing a survey questionnaire containing the framework and descriptive elements identified by Du Plessis (2003). This was distributed electronically to each individual and controlled to avoid duplication. The respondents had to evaluate the content in terms of their perception as experts in the field of project management. An open section was also available for the respondent to add any possible elements, not included, that might be viewed as important in describing a project management culture. The questionnaires were received electronically and noted to avoid double counting.

The data was analysed by using Lawshe's (1975) content validity technique. The validity of the items at this stage of the research was ensured by applying

- content validity criteria to ensure that the sample of items are representative of project management culture as perceived by experts; and

- criterion validity to ensure that the items are practical and reflected the theory.

The method of data gathering in the tool development part was based on steps 6 to 8 of De Vellis (1991). A survey questionnaire was used, comprising of 135 items derived from the data received and feedback from the experts in the verification part. A Likert-type rating scale, with an unequal 1-5 agreement format, was chosen. It was noted that the mid-range option of 3 in the scale could lead to respondents choosing the middle option; however, equal number options could have resulted in respondents' falling to one side. Data was gathered by distributing the survey questionnaire either by electronic-mail or by hand to the representative sample group of 494 . 
The process steps in scale development indicated by De Vellis (1991) and supported by Clark and Watson (1995) were applied. The 236 respondents' data (unspoiled returns) were analysed by means of a mainframe computer, assisted by the statisticians of the Department of Statistics at the University of Pretoria. The statistical programmes that were used are the SAS (1999) and BMDP (1993). Item analysis on the initial 135 items was done, per construct in the theoretical model, to determine construct validity by means of a Pearson correlation. Items with an item-scale correlation of $\leq 0,32$ were eliminated from the item pool.

Each of the four theoretical constructs/dimensions (Project process, People in projects, Project systems and structure, and Project environment) in the framework developed by Du Plessis (2003) was subjected to exploratory factor analysis (EFA), using the BMDP (1993). This was done to determine the underlying factor structure. The factors with eigenvalues of 1,0 and higher indicated on the scree plot were considered and were further subjected to factor analysis. The high level of interdependence amongst the items necessitated the use of Principal Factor Analysis with Direct Quartimin rotation of the items. The sorted rotated factor loading pattern was evaluated and items with a factor loading $<0,5$ (without influencing the theoretical construct of a holistic measurement tool) were eliminated. This is in line with the recommendations of Hofstede and Neuijen (1990). A Cronbach alpha coefficient for each factor was set at $>0,7$. It is noted that the closer to 1,0 the alpha was, the better, but the theoretical basis of the tool should also be supported as a holistic tool (Clark \& Watson, 1995). Confirmatory factor analysis of the individual scales was conducted to determine if the factors fit the construct.

The final scale with factors (the test instrument or assessment tool) derived from this research process, was subjected to item analysis to confirm the item correlation and to ensure that the final item correlation was $\leq 0,32$.

\section{Procedure}

Duncan (1984) argues that the roots of measurement lie in social processes and that these processes and measurement actually precede science: 'all measurement...is social measurement. Physical measures are made for social purposes' (Duncan, 1984). Whatever the initial motive of measurement, each area of science develops its own set of measurement procedures. In the social sciences, a typical measurement procedure is the use of questionnaires, and the variables of interest are part of a broader theoretical framework (De Vellis, 1991), which is indeed the process used in this study.

Since scale development is viewed as complex, the advise given by Clark and Watson (1995) on validity and the basic issues in scale development, as well as the eight steps described by De Vellis (1991) on the development of a scale instrument, also supported by Clark and Watson (1995) were used in this study.

\section{RESULTS}

The results of the content validity of project management culture dimensions and associated descriptive elements as perceived by project management experts can be seen in Table 3 .

The findings in table 3 show that experts might not regard the 'project environment' as such an important dimension in relation to the other three dimensions (project process, people in projects, and project systems and structure). This finding was to be expected, because attention to a holistic view is often neglected in project management, due to a more internal focus on the operational project environment and not on the project management environment. However, the results from the descriptive elements, within the project environment dimension, reveal respondents' acceptance of almost all the elements. Thus project environment still seems relevant as a dimension in the model and is thus not excluded.

TABLE 3

CONTENT VALIDITY OF PROJECT MANAGEMENT CULTURE DIMENSIONS AND ASSOCIATED DESCRIPTIVE ELEMENTS AS PERCEIVED BY PROJECT MANAGEMENT EXPERTS

\begin{tabular}{|c|c|c|}
\hline & \multicolumn{2}{|c|}{$N=$ Total respondents $(52)$} \\
\hline $\begin{array}{l}\text { DIMENSIONS and descriptive elements of } \\
\text { a project management culture }\end{array}$ & \multicolumn{2}{|c|}{$\begin{array}{l}\text { ne }=\text { Number of respondents } \\
\text { CVR }=\text { ne }-\mathrm{N} / 2 \\
\mathrm{~N} / 2 \\
\mathrm{CVR}=\text { Content validity } \\
\text { CVR }>50 \% \text { or } 0,50 \text { acceptable }\end{array}$} \\
\hline $\begin{array}{l}\text { What is the relevance of the following } \\
\text { dimensions and elements with regard to } \\
\text { contributing towards a project management } \\
\text { culture that leads to project success: }\end{array}$ & ne & CVR \\
\hline $\begin{array}{l}\text { A. Process (the manner in which the project } \\
\text { is designed, planned, and executed and } \\
\text { controlled-monitored). }\end{array}$ & 52 & 1,0 \\
\hline B. People (project stakeholders) & 44 & 0,85 \\
\hline $\begin{array}{l}\text { C. Structure and systems (project } \\
\text { methodology) }\end{array}$ & 32 & 0,62 \\
\hline D. Environment (internal and external) & 20 & 0,38 \\
\hline
\end{tabular}

\section{Content validity}

Sixty-three (63) out of the sixty-six (66), thus $95 \%$ of the descriptive elements included in the survey questionnaire assessing the validity have a content validity ratio of higher than 0,50 . The content validity index is $70 \%$. This shows that the theoretical construct of the project management culture framework and descriptive elements are viewed as valid and thus acceptable and can be used in an assessment tool.

Item analysis

The valid descriptive elements derived from the verification analysis were used to compile a 135 items survey questionnaire (variables), divided into a theoretical construct, based on the four dimension model/framework developed by $\mathrm{Du}$ Plessis $(2001,2003)$ which can be seen in Table 4.

TABLE 4

NUMBER OF ITEMS WITHIN THE FOUR-DIMENSION THEORETICAL CONSTRUCT

\begin{tabular}{cccc}
\hline $\begin{array}{c}1 \\
\text { Project process }\end{array}$ & $\begin{array}{c}3 \\
\text { People in projects }\end{array}$ & $\begin{array}{c}4 \\
\text { Project systems } \\
\text { and structure }\end{array}$ & $\begin{array}{c}\text { Project } \\
\text { environment }\end{array}$ \\
\hline 40 & 29 & 48 & 18 \\
\hline
\end{tabular}

Total number of items $=135$

Number of respondents $=236$

Each of the four theoretical constructs was subjected to item analysis, using SAS (1999). The items with a total item correlation of $\leq 0,32$ using Pearson's correlation technique were eliminated from the project management culture model within the four dimension theoretical construct. The results from the item analysis are:

- Project process construct

Five (5) of the initial 40 items were eliminated, leaving 35 items.

- People in projects

Eight (8) of the initial 29 items were eliminated, leaving 21 items. 
- Project structure and systems

Thirteen (13) of the initial 48 items were eliminated, leaving 35 items.

- Project environment

Two (2) of the initial 18 items were eliminated, leaving 16 items.

\section{Reliability}

Nunnally (1978) recommends a minimum level of 0,70 for a Cronbach alpha coefficient. Therefore the overall reliability of the items per dimension was highly acceptable, with Cronbach alpha coefficients of 0,$940 ; 0,908 ; 0,913$ and 0,802 respectively. The results can be seen in Table 5 .

\section{TABLE 5}

DECSRIPTIVE STATISTICS PER PROJECT MANAGEMENT CULTURE DIMENSION CONSTRUCT/SCALE $(\mathbf{N}=\mathbf{2 3 6})$

\begin{tabular}{lcccc}
\hline Dimension scale & 1 & 2 & 3 & 4 \\
\hline N of items & 40 & 29 & 48 & 18 \\
Mean score & 140,470 & 103,017 & 170,161 & 61,182 \\
Variance & 433,995 & 200,406 & 390,425 & 57,259 \\
Std. dev. & 20,833 & 14,156 & 19,759 & 7,567 \\
Skew (Sk) & $-0,117$ & $-0,309$ & $-0,206$ & $-0,430$ \\
Kurtosis (Ku) & $-0,513$ & $-0,321$ & $-0,087$ & 0,588 \\
Cronbach Alpha & 0,940 & 0,908 & 0,913 & 0,802 \\
\hline
\end{tabular}

The item inter-correlation, as reflected in Table 6 was high, which is expected of a construct that is supposed to be highly interdependent and systemic in nature. The remaining items under each project management culture dimension/construct were further subjected to Exploratory Factor Analysis (EFA) as reported in the following section on factor analysis.

TABLE 6

INTER-CORRELATIONS BETWEEN ITEMS IN THE DIMENSIONS

\begin{tabular}{lcccc}
\hline Dimension & 1 & 2 & 3 & 4 \\
\hline 1 & 1,000 & 0,863 & 0,902 & 0,800 \\
2 & 0,863 & 1,000 & 0,891 & 0,782 \\
3 & 0,902 & 0,891 & 1,000 & 0,825 \\
4 & 0,800 & 0,782 & 0,825 & 1,000 \\
\hline
\end{tabular}

Exploratory Factor analysis

A scree test was used to determine the number of factors with Kaiser's eigenvalues higher than 1,0 for each theoretical construct. The factors were chosen based on the results of the scree test, their percentage variance contribution as well as their Cronbach alpha coefficient. They were further subjected to factor analysis. The sorted rotated analysis results were used to analyse the factor loadings. Variables with factor loadings of $<0,5$ were eliminated to improve reliability, without compromising the theoretical framework of the holistic project management culture construct. The 'project systems and structure' construct divided into two separate factor scales i.e. 'project systems" and 'project structure'. The final result of the factor analyses indicated that 89 items divided into five factor scales that represented the project management culture assessment tool. The results can be seen in Table 7.
TABLE 7

SORTED ROTATED FACTOR ANALYSIS OF ITEMS OF PROJECT MANAGEMENT CULTURE ASSESSMENT TOOL

\begin{tabular}{|c|c|c|c|c|c|c|c|c|c|}
\hline \multicolumn{2}{|c|}{$\begin{array}{l}\text { Project } \\
\text { process }\end{array}$} & \multicolumn{2}{|c|}{$\begin{array}{l}\text { People in } \\
\text { projects }\end{array}$} & \multicolumn{2}{|c|}{$\begin{array}{l}\text { Project } \\
\text { systems }\end{array}$} & \multicolumn{2}{|c|}{$\begin{array}{l}\text { Project } \\
\text { structure }\end{array}$} & \multicolumn{2}{|c|}{$\begin{array}{c}\text { Project } \\
\text { environment }\end{array}$} \\
\hline $\begin{array}{l}\text { Items } \\
\mathrm{n}=27 \text { ) }\end{array}$ & $\begin{array}{l}\text { (Fac- } \\
\text { tor } \\
\text { ana- } \\
\text { lysis }\end{array}$ & $\begin{array}{l}\text { Items } \\
(\mathrm{n}=20)\end{array}$ & $\begin{array}{c}\text { Fac- } \\
\text { tor } \\
\text { ana- } \\
\text { lysis }\end{array}$ & $\begin{array}{l}\text { Items } \\
(\mathrm{n}=15)\end{array}$ & $\begin{array}{c}\text { Fac } \\
\text { tor } \\
\text { ana- } \\
\text { lysis }\end{array}$ & $\begin{array}{l}\text { Items } \\
(\mathrm{n}=15)\end{array}$ & $\begin{array}{c}\text { Fac- } \\
\text { tor } \\
\text { ana- } \\
\text { lysis }\end{array}$ & $\begin{array}{l}\text { Items } \\
(\mathrm{n}=12)\end{array}$ & $\begin{array}{c}\text { Fac- } \\
\text { tor } \\
\text { ana- } \\
\text { lysis }\end{array}$ \\
\hline 108 & 0,727 & 104 & 0,773 & 85 & 0,773 & 115 & 0,572 & 46 & 0,693 \\
\hline 71 & 0,714 & 75 & 0,755 & 134 & 0,663 & 43 & 0,562 & 122 & 0,652 \\
\hline 47 & 0,710 & 86 & 0,752 & 121 & 0,643 & 99 & 0,524 & 135 & 0,637 \\
\hline 82 & 0,699 & 110 & 0,740 & 65 & 0,631 & 31 & 0,506 & 50 & 0,619 \\
\hline 120 & 0,692 & 15 & 0,701 & 35 & 0,607 & 38 & 0,505 & 128 & 0,618 \\
\hline 100 & 0,684 & 139 & 0,669 & 62 & 0,592 & 51 & 0,505 & 68 & 0,594 \\
\hline 84 & 0,674 & 132 & 0,649 & vv124 & 0,534 & 107 & 0,504 & 117 & 0,590 \\
\hline 95 & 0,664 & 67 & 0,636 & 70 & 0,525 & 101 & 0,504 & 17 & 0,542 \\
\hline 28 & 0,635 & 96 & 0,614 & 11 & 0,518 & 141 & 0,450 & 54 & 0,511 \\
\hline 32 & 0,626 & 48 & 0,610 & 90 & 0,508 & 102 & 0,406 & 45 & 0,488 \\
\hline 24 & 0,612 & 72 & 0,602 & vv92 & 0,465 & 94 & 0,403 & 53 & 0,477 \\
\hline 123 & 0,605 & 127 & 0,541 & 111 & 0,385 & 105 & 0,393 & 9 & 0,448 \\
\hline 37 & 0,602 & 26 & 0,537 & 138 & 0,393 & 109 & 0,385 & & \\
\hline 66 & 0,600 & 16 & 0,532 & 141 & 0,417 & vv76 & 0,381 & & \\
\hline 69 & 0,589 & 34 & 0,508 & 133 & 0,318 & 49 & 0,390 & & \\
\hline 40 & 0,588 & 63 & 0,506 & & & & & & \\
\hline 106 & 0,559 & 6 & 0,504 & & & & & & \\
\hline 136 & 0,551 & 4 & 0,502 & & & & & & \\
\hline 52 & 0,540 & 27 & 0,501 & & & & & & \\
\hline 64 & 0,524 & 18 & 0,500 & & & & & & \\
\hline 39 & 0,524 & & & & & & & & \\
\hline 81 & 0,471 & & & & & & & & \\
\hline 19 & 0,444 & & & & & & & & \\
\hline 59 & 0,392 & & & & & & & & \\
\hline 61 & 0,389 & & & & & & & & \\
\hline 10 & 0,337 & & & & & & & & \\
\hline 20 & 0,309 & & & & & & & & \\
\hline
\end{tabular}

The final factor scale for the project management culture assessment tool can be seen in Table 8 .

TABLE 8

Final factor SCALE fOR THE PROJECT MANAGEMENT CULTURE assessment tool including Cronbach alpha (A)

\begin{tabular}{ccccc}
\hline $\begin{array}{c}\text { Factor } 1 \\
\text { Project } \\
\text { process }\end{array}$ & $\begin{array}{c}\text { Factor } 2 \\
\text { People in } \\
\text { projects }\end{array}$ & $\begin{array}{c}\text { Factor 3 } \\
\text { Project } \\
\text { structure }\end{array}$ & $\begin{array}{c}\text { Factor } 4 \\
\text { Project } \\
\text { systems }\end{array}$ & $\begin{array}{c}\text { Factor 5 } \\
\text { Project } \\
\text { environment }\end{array}$ \\
\hline$\alpha=0,928$ & $\alpha=0,915$ & $\alpha=0,855$ & $\alpha=0,822$ & $\alpha=0,853$ \\
27 items & 20 items & 15 items & 15 items & 12 items \\
\hline
\end{tabular}

After the completion of the exploratory factor analyses and the elimination of items confirmatory factor analysis was done on each scale. The results did not confirm that the scales were independent, which could be expected from an interdependent construct of items. A final item analysis was done on the 89 remaining items per factor root for each of the five-factor scales. The results of the final item analysis as illustrated in Table 9 show that all the items have a total item correlation of $>0,32$, which indicates that the items in the final tool have a high validity. 
TABLE9

DESCRIPTIVE STATISTICS OF THE FINAL ITEM ANALYSIS IN THE FIVE-FACTOR SCALE

\begin{tabular}{lccccc}
\hline Scale: & 1 & 2 & 3 & 4 & 5 \\
\hline N of Items & 27 & 20 & 15 & 15 & 12 \\
N of Examinees & 236 & 236 & 236 & 236 & 236 \\
Mean & 96,19 & 71,36 & 54,14 & 55,51 & 43,77 \\
Variance & 227,05 & 127,01 & 62,47 & 57,83 & 42,79 \\
Std. Dev. & 15,068 & 11,270 & 7,904 & 7,605 & 6,542 \\
Skew & $-0,144$ & $-0,267$ & $-0,119$ & $-0,632$ & $-0,346$ \\
Kurtosis & $-0,471$ & 0,427 & $-0,608$ & 0,796 & 0,071 \\
Alpha & 0,928 & 0,915 & 0,855 & 0,822 & 0,853 \\
\hline
\end{tabular}

The descriptive statistics in Table 9 show that the overall reliability of the items per dimension is highly acceptable, with Cronbach alpha coefficients of 0,$928 ; 0,915 ; 0,855 ; 0,822$ and 0,853 respectively, (higher than the acceptable minimum level of $0,70)$. The scale inter-correlation in Table 10 shows that the factors are still highly inter-correlated and this can be expected from an interdisciplinary, holistic construct of factors that are systemic in nature.

TABLE 10

FINAL SCALE INTERCORRELATIONS

\begin{tabular}{lccccc}
\hline Factor & $\mathbf{1}$ & $\mathbf{2}$ & $\mathbf{3}$ & $\mathbf{4}$ & $\mathbf{5}$ \\
\hline 1 & 1,000 & 0,881 & 0,815 & 0,809 & 0,830 \\
2 & 0,881 & 1,000 & 0,872 & 0,687 & 0,859 \\
3 & 0,815 & 0,872 & 1,000 & 0,574 & 0,833 \\
4 & 0,809 & 0,687 & 0,574 & 1,000 & 0,665 \\
5 & 0,830 & 0,859 & 0,833 & 0,665 & 1,000 \\
\hline
\end{tabular}

\section{DISCUSSION}

This study aimed 'to develop a reliable holistic assessment tool for measuring the project management culture, as operational culture, in organisations'. The principles of 'good scientific research' ('high ethical standards applied, adequate analysis and findings presented unambiguously') were applied.

Since project management is regarded as a holistic and interdisciplinary field, applied in an open system of multiple interdependent parts (sub-systems), an assessment of a project management culture in organisations should view such a culture as a holistic phenomenon, inclusive of strategies, structures, systems, processes, people's behaviour and the environment.

The framework on project management culture serves as a multi-disciplinary construct including the different dimensions of a project management culture. The high interrelatedness between the items of the different dimension further supports the interdependencies and interconnectivity that characterizes an open system. At the same time clear dimensions are visible indicating the construct validity of each facet.

This study has contributed on multiple levels to the fields of project management and organisational behaviour. This assessment tool can measure the current project management culture (an operational culture supportive of successful projects) of organisations. It can also be used as an informative (diagnostic) tool and a development tool to identify the areas for improvement to create a project management culture for project success.

Secondly, the availability of this assessment tool would enable organisations to assess or diagnose their present organisational culture's readiness for project work. The organisations that are hoping to reap the multiple benefits from getting involved in project management, will be able to use the tool "PMCAT" (project management culture assessment tool) to assess their present capability and thus could improve their chances to be more successful in doing project work. The PMCAT can also serve as a valuable tool for Human Resources Management in a strategic business role where a fine balance must be struck between managing people, processes, systems and structures within a changing environment.

Since the tool, 'PMCAT', does not focus on a particular industry or nationality, but on the organisation as a holistic operational entity, which has to perform in an open system, it could be used generically. Gaps in the current organisational culture, with regards to improving project work, can be identified, based on the five-factor scale. These identified gaps or possible limitations in being an organisation that can support projects more successfully, can facilitate actions to improve the situation, thereby optimising project work for continuous business improvement.

Furthermore the body of knowledge on project management and organisational culture was expanded and serve as a valuable contribution to the theory and research base of the interdisciplinary field of Project Management and Organisational Behaviour. The project management culture assessment tool (PMCAT) derived from this research should be able to distinguish between different sample groups to be useful as a diagnostic instrument.

The testing and evaluation of this diagnostic assessment tool to determine whether it can differentiate between organisations having project management culture, supporting projects or not, is a logical next step. The expansion of this study to a global sample will also contribute significantly to a globally relevant 'PMCAT'. A limitation of this study is that it is not industryspecific. To be globally useful and more customised for specific industries, further research needs to be conducted. This further research is already being persued.

\section{REFERENCES}

Ashkanasy, N. K., Wilderom, P.M, \& Peterson, M.F. (2000). Handbook of Organisational Culture and Climate. Sage Publications: London.

Ball, A. \& Asbury, S. (1989). The Winning Way. Jonathan Ball: Johannesburg.

BMDP Statistical Software, Inc. (1993). BMDP4M- Factor Analysis, Release 7.1, Los Angeles: CA.

Clark, L.A. \& Watson, D. (1995). Construct validity: Basic issues in objective scale development. Psychological Assessment, 7 (3), 309-319.

Cleland, D.I. (1994). Project Management - Strategic Design and Implementation, $2^{\text {nd }}$ ed. McGraw-Hill.

Cooke, R.A. \& Rousseau, D.M. (1988). Behavioral norms and expectations: A quantitative approach to the assessment of organisational culture. Group and Organisation Studies, 13, 245-273.

Cortina, J.M. (1993). What is a coefficient alpha? An examination of the theory and applications. Journal of Applied Psychology, 78 (1), 98-104.

De Vellis, R.F. (1991). Scale development: theory and application. Applied Social Research Method Series, 26. Sage Publications: London. 
Du Plessis, Y. (2001). Defining the concept of "Project culture" in organisations - A framework of guiding principles. Unpublished MBA Dissertation, University of Pretoria. Pretoria.

Du Plessis, Y. (2003). The Development of an Assessment Tool for Measuring Project Management Culture in Organisations. Unpublished Ph.D thesis, University of Pretoria: Pretoria.

Duncan, O.D. (1984). Notes on social measurement. Historical and critical. New York: Russel Sage.

Faules, D. (1982). The use of multimethods in the organisational setting. Western Journal of Speech Communication, 42, 150 161.

Furnham, A. \& Gunter, B. (1993). Corporate Assessment: Auditing a Company's Personality. Routledge: London.

Gorsuch, R.L. (1983). Factor Analysis, $2^{\text {nd }}$ ed. Hills-dale, NJ: Lawrence Erlbaum.

Gorsuch, R.L. (1997). Exploratory Factor Analysis: Its role in item analysis. Journal of Personality Assessment, 68 (3), 532-560.

Graham, R.J. \& Englund, R.L.(1997). Creating an Environment for Successful Projects. Jossey-Bass Publishers: San Francisco, California.

Gray, C.F. \& Larson, E.W. (2003). Project Management - The managerial process. Irwin McGraw-Hill: USA.

Hair, J.F., Anderson, R.E., Tatham, R.L. \& Black, W.C. (1998). Multivariate Data Analysis, $5^{\text {th }}$ Ed. Prentice -Hall International, Inc.

Hofstede, G. \& Neuijen, B. (1990). Measuring organisational cultures: A qualitative and quantitative study across twenty cases. Administrative Science Quarterly, 35 (2), 286-316.

Kaiser, H.F. (1970). A second-generation Little Jiffy. Psychometrika, 35, 401-415.

Kendra, K. \& Taplin, L.J. (2004). Project success. A cultural framework. Project Management Journal, 35 (1), 30-45.
Kerzner, H. (1997). Project management: A Systems Approach to Planning, Scheduling and Controlling, $5^{\text {th }}$ ed. Van Norstrand Reinhold: New York.

Knutson, J. (2001). Succeeding in Project-Driven OrganisationsPeople, Processes, and Politics. John Wiley \& Sons: New York.

Kotter J.P, \& Heskett, J.L. (1992). Corporate Culture and Performance. New York Free Press.

Lawshe, C.H. (1975). A quantitative approach to content validity. Personnel Psychology, 28, 563-575.

Lewis, D. (1996). The organisational culture saga- from OD to TQM: a critical review of the literature. Part 2- Application. Leadership \& Organisation Development Journal, 17 (2), 9-16.

Mouton, J. (2005). How to succeed in your Masters and Doctoral Studies. A South African Guide and Resource Book. Pretoria: Van Schaiks.

Nunnally, J. (1978). Psychometric Theory. New York: McGraw-Hill.

Rodrick, R. (1988). The emergent paradigm and organisational research. Paper presented at the meeting of the Western Speech Communication Association Convention, San Diego: CA.

Rousseau, D.M. (1990). Assessing organisational culture: The case of communication multiple methods. In B. Schneider (Ed.), Organisational climate and culture. Jossey-Bass: San Francisco.

SAS Institute, Inc. (1999). SAS 8.2, Version 8. Cary, NC.

Schein, E H. (1984). Coming to a new Awareness of Organisational Culture. Sloan Management Review, 25 (2), 3-15.

Turner, J.R. \& Simister, S.J. (2000). Gower Handbook of Project Management, $3^{\text {rd }}$ ed. Gower Publishing: Aldershot.

Wang, X. (2001). Dimensions and current status of project management culture. Project Management Journal, 32 (4), $4-17$. 